\title{
CAUSES AND VISUAL OUTCOME OF CHILDHOOD EYE INJURIES IN NIGERIA
}

\author{
R. E. UMEH and O. C. UMEH \\ Enugu, Nigeria
}

\begin{abstract}
SUMMARY
Two hundred and twenty-eight children of both sexes (152 males and 76 females) aged between 1 and 15 years treated for eye injuries at the University of Nigeria Teaching Hospital, Enugu, Nigeria were studied. The injuries were commonly sustained during domestic activities $(29.8 \%)$, at play or sports $(23.7 \%)$, in the schoolroom $(16.7 \%)$ and during farm work (10.1\%). Causative agents were mostly sticks, followed by stone missiles and other flying objects. There was a general delay in reporting to hospital in all types and degrees of severity of injuries, with only $28.5 \%$ reporting in the first 24 hours and as many as $\mathbf{1 0 . 5 \%}$ after 1 month. How quickly the patient came to hospital was determined more by social and economic factors than by sex, age and type of injury. Visual outcome was best in patients with mild non-penetrating injuries and worst in those with severe penetrating injuries. Amongst the latter the outcome was worse when the posterior segment was involved than when the injury involved only the anterior segment. Our study showed that there has been a change in the causation of childhood eye injuries in the country compared with reports of 25 years ago. The visual outcome in our patients was worse than in reports from developed countries. This was due mainly to delay in seeking specialist treatment and lack of sophistication of the treatment, especially in severe cases.
\end{abstract}

Eye injury is an important cause of unilateral visual impairment and blindness worldwide, ${ }^{1}$ the incidence being highest among children. ${ }^{2}$

In Nigeria, studies on childhood eye injuries ${ }^{3-5}$ have concentrated mainly on aetiological factors and types of injuries. The most comprehensive of such studies was that by Olurin ${ }^{3} 20$ years ago, in which she reported that most of the injuries occurred while the

From: Department of Ophthalmology, College of Medicine, University of Nigeria, Enugu Campus and University of Nigeria Teaching Hospital, Enugu, Nigeria.

Correspondence to: Dr Rich E. Umeh, Department of Ophthalmology, College of Medicine, University of Nigeria, Enugu Campus, Enugu, Nigeria. children were at play. The country has become more industrialised since then and life styles, including implements of work and playthings, have changed.

The present study was undertaken to re-evaluate the patterns of childhood eye injuries and their visual outcomes in order to determine whether there have been any changes in the aetiology and outcome of these injuries. Such information would be useful in designing specific interventions for preventing the injuries and improving their management.

\section{PATIENTS AND METHODS}

The study was carried out at the eye department of the University of Nigeria Teaching Hospital, Enugu, Nigeria. This is a tertiary care institution which draws its patients from the whole of South Eastern Nigeria - a population of about 22 million.

The period covered was between January 1991 and December 1993. A total of 228 children aged 1-15 years, treated for eye injury within this period, formed the subjects of the study. History of their injury was recorded and eye examinations were carried out by one of the authors (R.E.U.) assisted by one resident ophthalmologist (O.C.U.). Pre- and post-treatment visual acuities were measured using Snellen's chart for distance and graded according to WHO criteria. ${ }^{6}$ This was done in all the patients except those who could not co-operate or whose injuries would not allow the evaluation. A slit lamp biomicroscope was used to examine the anterior segment. The posterior segment, where the media allowed, was examined with the direct and indirect ophthalmoscope.

For the purpose of this study, eye injuries were classified into penetrating and non-penetrating. Penetrating injuries were those in which there was at least a laceration of the globe. This was described as mild if the laceration was confined to superficial layers of the anterior part of the eye and severe when there was a full-thickness laceration. The full-thickness lacerations were further subdivided into those 
affecting the anterior segment only, both anterior and posterior segments, or the posterior segment only. In addition, there might be uveal prolapse and/ or lens rupture. The injury was defined as nonpenetrating when the globe was intact following a contusional injury. Non-penetrating injury was described as mild when the patient had only ciliary injection with or without photophobia; and severe when there was an associated intraocular haemorrhage. In addition, the lens might be subluxated or dislocated. Early complications were defined as those found on examination of the eye on admission, in patients who came within 24 hours of their injuries. All other complications were referred to as late complications.

Treatment given to the patient depended on the nature of the injury sustained. All children who had hyphaema as a result of non-penetrating injury were admitted to hospital. They were nursed in bed, with the head of the bed tilted at an angle of $45^{\circ}$ and their head propped up with more than one pillow. The affected eye was padded in children over the age of 5 years. Some of the patients who had hyphaema developed secondary glaucoma. This was treated with acetazolamide and timolol eye drops $0.5 \%$. Acetazolamide was administered as tablets, $125 \mathrm{mg}$ three times daily in children below 10 years and 250 $\mathrm{mg}$ in those above 10 years. Timolol was instilled twice a day. Pilocarpine eye drops $4 \%$ were given in place of timolol in children with a history of asthma. If there was marked ciliary injection, betamethasone eye drops were added to the treatment. Where the pressure was not responding and the hyphaema not resolving, surgical evacuation of the blood was carried out in theatre. The fundus was examined under mydriasis achieved with phenylephrine $10 \%$ and mydrilate $1 \%$ after the hyphaema had cleared. Children who had corneal burns were admitted also and the eye treated with antibiotic eye drops and ointment.

Surgery was carried out on patients with severe non-penetrating injuries. This took the form of paracentesis in case of unresolving total hyphaema with raised intraocular pressure, or extraction of the lens when this was dislocated into the anterior chamber. In the case of penetrating injuries, corneal or corneo-scleral lacerations were sutured with $8 / 0$ virgin silk. Prolapsed iris was reposited in patients whose injuries occurred within 24 hours of presentation but abscised in those reporting later than 24 hours. Where the lens was ruptured, a total lens washout was performed at the same time as the corneal repair if the lens was completely opaque or soft lens matter was present at time of assessment. For cataract, an incision was made at the limbus after a primary repair of the corneal wound. Air was injected into the anterior chamber to reconstitute it and allow adequate space for the irrigation and aspiration of the lens matter without further damage to the corneal endothelium. The anterior chamber was irrigated with normal saline using a two-way irrigation canula. Where there was rupture of the posterior capsule with vitreous prolapse, an anterior vitrectomy was done using De Wecker's scissors and damp small pieces of cotton wool rolled into spears. A peripheral or broad iridectomy was done depending on the state of the iris following the injury. Corneo-scleral wounds were closed with $8 / 0$ virgin silk. All surgical procedures were carried out in theatre using a $\times 4$ magnification head loupe. Microsurgical techniques were not used because the necessary equipment was not available in the hospital at the time of the study. Primary enucleation and evisceration were carried out in 7 patients, 4 with a badly lacerated eyeball and 3 with panophthalmitis respectively.

After discharge from hospital, patients were seen weekly for the first month and thereafter 2-weekly or monthly, depending on the recovery rate, for up to 6 months. A comprehensive evaluation of the eye, including refraction where this was indicated, was undertaken at 6 weeks, 3 months and 6 months. If the eye had settled, the patient was discharged finally at 6 months. Otherwise they were asked to continue to attend until they either stabilised and were discharged, or they dropped out. Visual acuity recorded during the last visit was used as final visual acuity for this report.

Refraction for aphakic eyes was done at 6 weeks and 3 months after discharge from hospital to assess the level of visual improvement. Aphakic spectacles were given only in cases where the injured eye was the better eye. They were not given otherwise because of the problem of uniocular correction with aphakic spectacles. Contact or intraocular lenses were not available in the hospital at the time of the study.

A case record form was completed for each patient and included such information as name, sex and age, time of injury, time of reporting after injury, type of injury, cause or activity at time of injury, complications, and measures taken before reporting to hospital.

\section{Data Management}

Data storage and analysis were done using Epi Info software (Epi Info version 5.01, public domain, USA).

\section{RESULTS}

Two hundred and twenty-eight patients were studied (Table I). Of these, 76 (33.3\%) were females while $152(66.7 \%)$ were males - a female to male ratio of $1: 2$. The mean age of the children was 9.6 years \pm 
Table I. Age and sex distribution of 228 patients in relation to nature of injuries

\begin{tabular}{|c|c|c|c|c|c|c|c|c|}
\hline \multirow[b]{3}{*}{ Age (years) and sex } & \multicolumn{4}{|c|}{ Penetrating } & & & & \\
\hline & \multirow[b]{2}{*}{ Mild } & \multicolumn{3}{|c|}{ Severe } & \multicolumn{2}{|c|}{ Non-penetrating } & \multicolumn{2}{|c|}{ Total } \\
\hline & & Ant. & Ant. + Post. & Post. & Mild & Severe & No. & $\%$ \\
\hline \multicolumn{9}{|l|}{$0-5$} \\
\hline Male & 0 & 4 & 2 & 0 & 5 & 3 & 14 & 6.1 \\
\hline Female & 1 & 2 & 0 & 0 & 3 & 3 & 9 & 3.9 \\
\hline Total & 1 & 6 & 2 & 0 & 8 & 6 & 23 & 10.1 \\
\hline \multicolumn{9}{|l|}{$6-10$} \\
\hline Male & 8 & 11 & 8 & 3 & 21 & 30 & 81 & 35.5 \\
\hline Female & 1 & 7 & 4 & 1 & 13 & 5 & 31 & 13.6 \\
\hline Total & 9 & 18 & 12 & 4 & 34 & 35 & 112 & 49.1 \\
\hline \multicolumn{9}{|l|}{$11-15$} \\
\hline Male & 4 & 9 & 6 & 4 & 13 & 21 & 57 & 25.0 \\
\hline Female & 6 & 7 & 3 & 3 & 11 & 6 & 36 & 15.8 \\
\hline Total & 10 & 16 & 9 & 7 & 24 & 27 & 93 & 40.8 \\
\hline \multicolumn{9}{|l|}{ All ages } \\
\hline Male & 12 & 24 & 16 & 7 & 39 & 54 & 152 & 66.7 \\
\hline Female & 8 & 16 & 7 & 4 & 27 & 14 & 76 & 33.3 \\
\hline Total & 20 & 40 & 23 & 11 & 66 & 68 & 228 & 100 \\
\hline
\end{tabular}

Ant., anterior segment injury only; Ant. + Post., anterior + posterior segment injury; Post., posterior segment injury only.

3.14 (SD). There were 94 children with penetrating injuries and 134 with non-penetrating injuries. Of the penetrating injuries, 20 were mild while 74 were severe. Of the severe, 40 patients had anterior segment injuries only, 23 patients had both anterior and posterior segment injuries and 11 patients had posterior segment injuries only. Of the non-penetrating injuries, 66 were mild while 68 were severe.

\section{Complications Arising from the Injuries}

The various complications observed are summarised in Table II. Early complications (as defined under Patients and Methods above) were mainly intraocular haemorrhage, traumatic cataract and secondary

Table II. Types of complications and their frequencies

\begin{tabular}{|c|c|c|c|}
\hline & \multicolumn{3}{|c|}{ Types of injury } \\
\hline & Penetrating & $\begin{array}{c}\text { Non- } \\
\text { Penetrating }\end{array}$ & Total \\
\hline Early complications & $(n=29)$ & $(n=23)$ & $(n=52)$ \\
\hline Intraocular haemorrhage & 6 & 21 & 27 \\
\hline Traumatic cataract & 17 & 4 & 21 \\
\hline Secondary glaucoma & 4 & 8 & 12 \\
\hline $\begin{array}{l}\text { Subluxation or dislocation } \\
\text { of lens }\end{array}$ & 0 & 4 & 4 \\
\hline Traumatic uveitis & 2 & 6 & 8 \\
\hline Panophthalmitis & 3 & 0 & 3 \\
\hline Late complications & $(n=45)$ & $(n=22)$ & $(n=67)$ \\
\hline Corneal opacity & 36 & 6 & 42 \\
\hline Anterior/ciliary staphyloma & 8 & 3 & 11 \\
\hline Secondary glaucoma & 0 & 2 & 2 \\
\hline $\begin{array}{l}\text { Retinal oedema/scar/ } \\
\text { macular hole }\end{array}$ & 5 & 3 & 8 \\
\hline Traumatic cataract & 2 & 7 & 9 \\
\hline Phthisis bulbi & 9 & 6 & 15 \\
\hline $\begin{array}{l}\text { Others (eyelid deformity, } \\
\text { corneal ulcers, orbital } \\
\text { cellulitis) }\end{array}$ & 4 & 18 & 22 \\
\hline
\end{tabular}

$\overline{\text { Some children had more than one complication and some did not }}$ have any.

$n$, number of patients with the complications. glaucoma. Twenty-nine (29) patients with penetrating and 23 patients with non-penetrating injuries had early complications. Of 27 patients who had intraocular haemorrhage, in 21 of them it resulted from a non-penetrating injury. By contrast, of 21 patients who had traumatic cataract, in the majority (17) of them it resulted from penetrating injury.

Late complications were observed in 45 patients with penetrating injuries and 22 patients with nonpenetrating injuries. The complications were mainly corneal opacity, phthisis bulbi and anterior and ciliary staphyloma. Of 42 patients with corneal opacity, 36 were from penetrating injuries. Fifteen patients had phthisis bulbi, 9 as a result of penetrating injuries; 11 patients had staphyloma, 8 from penetrating injuries. There was, however, a miscellaneous group of complications including eyelid deformity, corneal ulcers and orbital cellulitis. They formed $20.2 \%(22 / 109)$ of the late complications, and resulted mostly from non-penetrating injuries (18/22).

For both early and late complications the cumulative number of times the complications occurred was greater than the number of patients with complications. This was because some patients had more than one complication.

\section{Activities During which Injury Occurred and Causes of Injury}

Tables III and IV show the activities the children were engaged in when the injury was sustained and the causative agents. Sixty-eight $(29.8 \%)$ of these children were injured while engaged in domestic activities such as fetching or splitting of firewood, weeding the garden or manual cracking of palm kernel with stones to extract the seeds. Injuries arose when the eyes were hit by flying pieces of wood, 
Table III. Activity of patient at the time of injury

\begin{tabular}{|c|c|c|c|c|c|c|}
\hline \multirow[b]{3}{*}{ Activity } & \multicolumn{6}{|c|}{ No. of children } \\
\hline & \multicolumn{2}{|c|}{ Male } & \multicolumn{2}{|c|}{ Female } & \multicolumn{2}{|c|}{ Total } \\
\hline & No. & $\%$ & No. & $\%$ & No. & $\%$ \\
\hline Domestic & 32 & 21.1 & 36 & 47.4 & 68 & 29.8 \\
\hline Play or sports & 44 & 28.9 & 10 & 13.2 & 54 & 23.7 \\
\hline Schoolroom accidents & 20 & 13.2 & 18 & 23.7 & 38 & 16.7 \\
\hline Assaults outside school & 18 & 11.8 & 4 & 5.3 & 22 & 9.6 \\
\hline Farming activities & 17 & 11.2 & 6 & 7.9 & 23 & 10.1 \\
\hline Road traffic accidents & 4 & 2.6 & 1 & 1.3 & 5 & 2.2 \\
\hline Firearms & 4 & 2.6 & 0 & 0 & 4 & 1.8 \\
\hline Unknown & 13 & 8.6 & 1 & 1.3 & 14 & 6.1 \\
\hline Total & 152 & 100 & 76 & 100 & 228 & 100 \\
\hline
\end{tabular}

sticks, twigs, grass blades or chips of palm kernel shells. The second most common activity during which injuries were sustained was play or sports. Fifty-four children $(23.7 \%)$ were affected in this way, from flying pieces of sticks, from catapulted stones or from 'melina' fruit used as hand-thrown missiles. These resulted in mostly contusional injuries. Thirtyeight children $(16.7 \%)$ sustained injuries while in the schoolroom. These injuries were commonly sustained accidentally with pencil tips or the teacher's cane, by falling on to the edge of desks or from assaults in class by classmates. Assaults outside school and farm-related injuries were the causes of injury in $22(9.6 \%)$ and $23(10.1 \%)$ children respectively. In the former situation, finger nail injury and fist-blow were the most common causes while tree branches, grass blades and twigs were responsible in the latter. Road traffic accidents and firearms were infrequent cause of eye injuries in this study. There was a marked male-female difference in the relative importance of the activities leading to injury. Whereas for girls the commonest activities were domestic chores followed by school room accidents and play or sports, for boys the commonest activity was play or sports followed by domestic chores and school accidents.

\section{Interval Between Injury and Presentation at Hospital}

Table $\mathrm{V}$ shows the interval between time of injury and presentation at the hospital. This ranged from

Table IV. Agents causing injury

\begin{tabular}{lcc}
\hline Agents of injury & No. & $\%$ \\
\hline Sticks/twigs/grass blades & 71 & 31.1 \\
Stone/other catapulted missiles & 32 & 14 \\
Road traffic accident/falls onto objects & 23 & 10.1 \\
Palm kernel shells/frond/fruits/seeds & 19 & 8.3 \\
Finger nail injury/fist-blow & 16 & 7.0 \\
Knife/metal wire/iron trap & 13 & 5.7 \\
Piece of broken bottle/sharp plastics & 8 & 3.5 \\
Sand/gravel/cement dust & 6 & 2.6 \\
Football & 5 & 2.2 \\
Guns/explosives & 4 & 1.8 \\
Others & 31 & 13.6 \\
Total & 228 & 100 \\
\hline
\end{tabular}

within 24 hours to more than 1 month (mean interval, 16 days) for both penetrating and nonpenetrating injuries. Only 65 patients $(28.5 \%)$ presented within 24 hours of injury. Of these, 43 were males and 22 were females - a ratio of $2: 1$. One hundred and three patients (45.2\%), 68 males and 35 females, were seen after the first day but within 7 days of their injuries. In the group that presented between 8 days and 1 month, there were 22 males and 14 females, which gives a male: female ratio of $1.6: 1$. For the group who presented after 1 month, comprising 19 males and 5 females, the male : female ratio was $3.8: 1$. Given that the overall male: female ratio was 2:1 there was no sex difference in early attendance to hospital up to 7 days but there was male preponderance $(3.8: 1)$ in those who attended later than 1 month. Also, considering that $50 \%$ of patients with mild penetrating injuries came within 24 hours whereas the corresponding figures for the other subgroups were between $20 \%$ and $32 \%$, it would appear that there was a tendency for patients with mild penetrating injuries to report immediately to hospital. However, this trend disappeared if attendance in the first week after the accident was considered. This showed that $85 \%$ of mild penetrating, $63.5 \%$ of severe penetrating, $83.3 \%$ of mild nonpenetrating and $72.1 \%$ of severe non-penetrating injuries came to hospital within the first week, so that the difference between mild penetrating and other types of injuries had been partially lost by the end of the first week. At the other extreme, whereas no patient with mild penetrating injury waited more than a month to come to hospital, $12.2 \%, 6.1 \%$ and $16.2 \%$ of patients with severe penetrating, mild nonpenetrating and severe non-penetrating injuries respectively reported after 1 month.

The delay between time of injury and presentation at the teaching hospital was due to several reasons, including the distance patients had to travel to get to the hospital, cost of the journey and hospital charges. Some of the patients preferred traditional eye medication or self-medication. A few patients had been delayed at the lower-level hospital or health centre where inexperienced medical personnel 
Table V. Interval between injury and presentation at the teaching hospital

\begin{tabular}{|c|c|c|c|c|c|c|c|c|c|}
\hline \multirow[b]{3}{*}{ Nature of injury } & \multicolumn{9}{|c|}{ Time interval } \\
\hline & \multicolumn{2}{|c|}{$0-24$ hours } & \multicolumn{2}{|c|}{2 days- 1 week } & \multicolumn{2}{|c|}{8 days -1 month } & \multicolumn{2}{|c|}{$>1$ month } & \multirow{2}{*}{$\frac{\text { Total }}{\text { No. }}$} \\
\hline & No. & $\%$ & No. & $\%$ & No. & $\%$ & No. & $\%$ & \\
\hline $\begin{array}{l}\text { Penetrating } \\
\text { Mild } \\
\text { Severe }\end{array}$ & $\begin{array}{l}10 \\
20\end{array}$ & $\begin{array}{l}50 \\
27.0\end{array}$ & $\begin{array}{r}7 \\
27\end{array}$ & $\begin{array}{l}35 \\
36.5\end{array}$ & $\begin{array}{r}3 \\
18\end{array}$ & $\begin{array}{l}15 \\
24.3\end{array}$ & $\begin{array}{l}0 \\
9\end{array}$ & $\begin{array}{c}0 \\
12.2\end{array}$ & $\begin{array}{l}20 \\
74\end{array}$ \\
\hline $\begin{array}{l}\text { Non-penetrating } \\
\text { Mild } \\
\text { Severe }\end{array}$ & $\begin{array}{l}21 \\
14\end{array}$ & $\begin{array}{l}31.8 \\
20.6\end{array}$ & $\begin{array}{l}34 \\
35\end{array}$ & $\begin{array}{l}51.5 \\
51.5\end{array}$ & $\begin{array}{l}7 \\
8\end{array}$ & $\begin{array}{l}10.6 \\
11.8\end{array}$ & $\begin{array}{r}4 \\
11\end{array}$ & $\begin{array}{r}6.1 \\
16.2\end{array}$ & $\begin{array}{l}66 \\
68\end{array}$ \\
\hline $\begin{array}{l}\text { Total } \\
\mathrm{M}: \mathrm{F} \text { ratio }\end{array}$ & 65 & 28.5 & 103 & 45.2 & 36 & 15.8 & 24 & 10.5 & $\begin{array}{c}228 \\
152: 76\end{array}$ \\
\hline
\end{tabular}

continued with inappropriate treatment without realising the extent of the injury and that the patient needed to be referred to an eye specialist urgently.

\section{Prior Treatment}

Of the 228 patients, $94(41.2 \%)$ reported directly to the teaching hospital or were referred there from a lower-level hospital after their injuries. Thirty-seven $(16.2 \%)$ treated themselves unsuccessfully either with eye drops bought from patent medicine stores or herbal eye 'remedies', before presenting themselves at the teaching hospital. The remaining 97 $(42.5 \%)$ came to the hospital only when their eye condition started deteriorating.

\section{Overall Visual Outcome}

Visual acuity before treatment was recorded for patients in whom it could be obtained. The posttreatment visual acuity recorded was the final one measured. Among the patients with mild penetrating injuries ( $n=20$, Table VII) pre-treatment visual acuity was $6 / 6$ in 3 patients $(15 \%)$, ranged between $6 / 9$ and $6 / 18$ in 10 children $(50 \%)$, between $6 / 24$ and $6 / 60$ in 5 children $(25 \%)$ and was not measurable in 2 children (10\%). On discharge, all 20 were evaluable. Seven children had a visual acuity of $6 / 6,5$ between $6 / 9$ and $6 / 18$, and another 5 between $6 / 24$ and 6/60. In 3 patients visual acuity ranged between $3 / 60$ and perception of light (PL); this included the 2 whose visual acuity was not measurable initially.

Of 66 patients with mild non-penetrating injuries (Table VI), in 3 the visual acuity was not measurable pre-treatment. Seven had $6 / 6$ vision, 53 had between $6 / 9$ and $6 / 18$ while 3 had from $6 / 24$ to $6 / 60$. After treatment, all had a measurable visual acuity, with 53 having normal visual acuity of $6 / 6$. Twelve had acuities ranging between $6 / 9$ and $6 / 18$ and 1 patient fell in the range between $6 / 24$ and $6 / 60$. Forty-six patients $(82.1 \%)$ regained normal vision, indicating that mild non-penetrating injuries had good prognosis in this series.

Among the 68 patients with severe non-penetrating injuries (Table VI), in 4 the visual acuity was measurable pre-treatment, none had $6 / 6$ vision and 6 had between $6 / 9$ and 6/18. Twenty-four patients had acuities ranging between $6 / 24$ and $6 / 60,27$ had $3 / 60$ to PL, while 5 had no perception of light (NPL). After treatment, all had a measurable visual acuity, with $18(26.5 \%)$ regaining normal vision. Twenty-one patients had visual acuities ranging between $6 / 9$ and $6 / 18$, while in 17 it ranged between 6/24 and 6/60. Six children had acuities between 3/60 and PL and 6 had NPL. In general a higher percentage of the patients in these three groups (mild penetrating, mild nonpenetrating and severe non-penetrating) fell in the reasonably good range of vision (that is, above 6/24)

Table VI. Pre- and post-treatment visual acuity in patients with non-penetrating injuries

\begin{tabular}{|c|c|c|c|c|c|c|c|c|c|c|c|c|c|c|}
\hline \multirow[b]{3}{*}{ Age (years) } & \multicolumn{14}{|c|}{ Pre- and post-treatment visual acuity } \\
\hline & \multicolumn{2}{|c|}{ NA } & \multicolumn{2}{|c|}{$6 / 6$} & \multicolumn{2}{|c|}{$6 / 9-6 / 18$} & \multicolumn{2}{|c|}{$6 / 24-6 / 60$} & \multicolumn{2}{|c|}{ 3/60-PL } & \multicolumn{2}{|c|}{ NPL } & \multicolumn{2}{|c|}{ Total } \\
\hline & $\mathrm{a}$ & $\mathrm{b}$ & a & $\mathrm{b}$ & a & $\mathrm{b}$ & $\mathrm{a}$ & $\mathrm{b}$ & $\mathrm{a}$ & $\mathrm{b}$ & $\mathrm{a}$ & $\mathrm{b}$ & a & $\mathrm{b}$ \\
\hline \multicolumn{15}{|l|}{$\overline{\text { Mild }}$} \\
\hline $0-15$ & 3 & 0 & 0 & 6 & 4 & 2 & 1 & 0 & 0 & 0 & 0 & 0 & 8 & 8 \\
\hline $6-10$ & 0 & 0 & 2 & 29 & 31 & 5 & 1 & 0 & 0 & 0 & 0 & 0 & 34 & 34 \\
\hline $11-15$ & 0 & 0 & 5 & 18 & 18 & 5 & 1 & 1 & 0 & 0 & 0 & 0 & 24 & 24 \\
\hline Total & 3 & 0 & 7 & 53 & 53 & 12 & 3 & 1 & 0 & 0 & 0 & 0 & 66 & 66 \\
\hline \multicolumn{15}{|l|}{ Severe } \\
\hline $0-15$ & 4 & 0 & 0 & 3 & 0 & 1 & 2 & 1 & 0 & 0 & 0 & 1 & 6 & 6 \\
\hline $6-10$ & 0 & 0 & 0 & 10 & 4 & 9 & 12 & 9 & 15 & 3 & 4 & 4 & 35 & 35 \\
\hline $11-15$ & 0 & 0 & 0 & 5 & 4 & 11 & 10 & 7 & 12 & 3 & 1 & 1 & 27 & 27 \\
\hline Total & 4 & 0 & 0 & 18 & 8 & 21 & 24 & 17 & 27 & 6 & 5 & 6 & 68 & 68 \\
\hline
\end{tabular}

$a$, number of patients pre-treatment; b, number of patients post-treatment; NA, not able to obtain visual acuity. 
Table VII. Pre- and post-treatment visual acuity in patients with penetrating injuries

\begin{tabular}{|c|c|c|c|c|c|c|c|c|c|c|c|c|c|c|}
\hline \multirow[b]{3}{*}{ Age (years) } & \multicolumn{14}{|c|}{ Pre- and post-treatment visual acuity } \\
\hline & \multicolumn{2}{|c|}{ NA } & \multicolumn{2}{|c|}{$6 / 6$} & \multicolumn{2}{|c|}{$6 / 9-6 / 18$} & \multicolumn{2}{|c|}{$6 / 24-6 / 60$} & \multicolumn{2}{|c|}{ 3/60-PL } & \multicolumn{2}{|c|}{ NPL } & \multicolumn{2}{|c|}{ Total } \\
\hline & a & $\mathrm{b}$ & a & $\mathrm{b}$ & a & $\mathrm{b}$ & a & $\mathrm{b}$ & $\mathrm{a}$ & $\mathrm{b}$ & $\mathrm{a}$ & $\mathrm{b}$ & a & $\mathrm{b}$ \\
\hline \multicolumn{15}{|l|}{ Mild } \\
\hline $0-15$ & 1 & 0 & 0 & 0 & 0 & 0 & 0 & 1 & 0 & 0 & 0 & 0 & 1 & 1 \\
\hline $6-10$ & 1 & 0 & 1 & 4 & 5 & 2 & 2 & 2 & 0 & 1 & 0 & 0 & 9 & 9 \\
\hline $11-15$ & 0 & 0 & 2 & 3 & 5 & 3 & 3 & 2 & 0 & 2 & 0 & 0 & 10 & 10 \\
\hline Total & 2 & 0 & 3 & 7 & 10 & 5 & 5 & 5 & 0 & 3 & 0 & 0 & 20 & 20 \\
\hline \multicolumn{15}{|l|}{ Severe } \\
\hline $0-15$ & 5 & 0 & 0 & 1 & 0 & 0 & 1 & 2 & 0 & 3 & 2 & 2 & 8 & 8 \\
\hline $6-10$ & 3 & 0 & 0 & 3 & 2 & 2 & 5 & 18 & 18 & 3 & 6 & 8 & 34 & 34 \\
\hline $11-15$ & 0 & 0 & 0 & 3 & 2 & 6 & 5 & 9 & 18 & 7 & 7 & 7 & 32 & 32 \\
\hline Total & 8 & 0 & 0 & 7 & 4 & 8 & 11 & 29 & 36 & 13 & 15 & 17 & 74 & 74 \\
\hline
\end{tabular}

$a$, number of patients pre-treatment; $b$, number of patients post-treatment; NA, not able to obtain visual acuity.

after treatment than before. However, 5 of the patients with severe non-penetrating injuries ended up with a painful blind eye. The age of the patient did not appear to have any influence on the visual outcome.

Table VIII summarises the visual outcome in patients with different grades of severe penetrating injury. Among 8 patients whose visual acuity could not be assessed at presentation, 2 had anterior segment injuries only while 3 had both anterior and posterior segment injuries and another 3 posterior segment injuries only. After treatment, all had a measurable visual acuity. None of the patients had $6 / 6$ vision at presentation, but after treatment 6 patients with anterior segment injury and 1 patient with both anterior and posterior segment injuries recovered $6 / 6$ vision. All 4 patients with $6 / 9$ to $6 / 18$ vision pre-treatment had anterior segment injuries only. After treatment they retained vision within the same range and 4 additional patients improved to this level. Among 11 patients who had acuities between $6 / 24$ and $6 / 60$ pre-treatment, 4 sustained anterior segment injuries while 7 had both anterior

Table VIII. Visual outcome in patients with different grades of severe penetrating injury

\begin{tabular}{|c|c|c|c|c|c|}
\hline \multirow{2}{*}{\multicolumn{2}{|c|}{ Visual acuity }} & \multicolumn{4}{|c|}{$\begin{array}{l}\text { No. of patients in different grades of } \\
\text { penetrating injury }\end{array}$} \\
\hline & & $\begin{array}{c}\text { Ant. } \\
(n=40)\end{array}$ & $\begin{array}{l}\text { Ant. + Post. } \\
\quad(n=23)\end{array}$ & $\begin{array}{l}\text { Post. } \\
(n=11)\end{array}$ & $\begin{array}{c}\text { Total } \\
(n=74)\end{array}$ \\
\hline \multirow[t]{2}{*}{ NA } & a & 2 & 3 & 3 & 8 \\
\hline & b & 0 & 0 & 0 & 0 \\
\hline \multirow[t]{2}{*}{$6 / 6$} & a & 0 & 0 & 0 & 0 \\
\hline & b & 6 & 1 & 0 & 7 \\
\hline \multirow[t]{2}{*}{ 6/9-6/18 } & a & 4 & 0 & 0 & 4 \\
\hline & b & 7 & 1 & 0 & 8 \\
\hline \multirow[t]{2}{*}{$6 / 24-6 / 60$} & a & 4 & 7 & 0 & 11 \\
\hline & b & 16 & 10 & 3 & 29 \\
\hline \multirow[t]{2}{*}{ 3/60-PL } & $\mathrm{a}$ & 28 & 8 & 0 & 36 \\
\hline & b & 9 & 4 & 0 & 13 \\
\hline \multirow[t]{2}{*}{ NPL } & a & 2 & 5 & 8 & 15 \\
\hline & b & 2 & 7 & 8 & 17 \\
\hline
\end{tabular}

Ant., anterior segment injury; Post., posterior segment injury. a, pre-treatment; $b$, post-treatment. and posterior segment injuries. After treatment, a total of 29 patients retained vision between $6 / 24$ and $6 / 60 ; 16$ of these had had anterior segment injuries only, 10 had both anterior and posterior segment injuries while 3 had posterior segment injuries only.

Visual acuities between $3 / 60$ and PL were recorded for 36 patients before treatment. Of these, 28 had anterior segment injuries, while 8 had both anterior and posterior segment injuries. After treatment, the number was reduced to 13 . This included 9 patients with anterior segment injuries and 4 with injuries involving both anterior and posterior segments. Of the 15 patients who had NPL on presentation, 2 had injuries involving the anterior segment only, 5 had both anterior and posterior segment injuries while 8 sustained posterior segment injuries only. After treatment, the number of patients in this group increased by 2 , both of them in the group with both anterior and posterior segment injuries.

On the whole Table VIII shows that visual outcome was poor in patients whose penetrating injury involved the posterior segment, whether alone or together with the anterior segment. Most of the improvements were in the group with anterior segment injuries only. As in the other groups, age did not appear to have any effect on the outcome of severe penetrating injury (Table VII).

Outpatient follow-up period ranged from 1 week to 6 months for all injuries, with a mean follow-up period of 13.5 weeks. Eighty-three of the 228 patients attended for less than 3 months before their final discharge. Fifteen patients of the 83 attended only once after their discharge from hospital. Eight patients who had visual acuity of $6 / 9$ or better in the injured eye at the time of discharge from hospital did not attend for follow-up.

\section{DISCUSSION}

Eye injuries in children remain a problem worldwide. There is commonly a male preponderance, the 
male : female ratio of $2: 1$ in this study being one of the lowest in the literature. ${ }^{7-10}$ The rate of injuries increases with the increasing activity that comes with increasing age, especially in male children. The causative agents and circumstances of the injuries are various and may differ from country to country. In Nigeria, ${ }^{3-5}$ the causative agents consist mainly of vegetable matter, but in developed countries ${ }^{8,11}$ they consist mainly of missiles, darts and bullets. Injuries with vegetable matter are known to lead to complications such as fungal corneal ulcer and panophthalmitis with poor visual prognosis.

Type of injury was a major risk factor for poor visual outcome in this study. It was noted that patients who had involvement of the posterior segment had a poor visual outcome. Apart from the fact that such injuries usually have a poor prognosis, ${ }^{12,13}$ the lack of microsurgical facilities in our study area added to the poor results. The relatively large percentage of patients with severe penetrating injuries in this study and the surprising fact that this was the group that presented to hospital later than the others, further explain the poor results in the group. Neither the age nor the sex of the child made any difference to the time between injury and presentation to hospital, except for the slight preponderance of males amongst those presenting very late ( $\geqslant 1$ month). Rather, social and economic factors formed the main risk factors for delay in presentation to hospital, underlining the role of these factors in the adverse health situation of developing countries. However, when the visual outcome in the present study is compared with that in the study done in the same area in $1988,{ }^{7}$ there seems to have been an improvement with time.

The majority of the eye injuries could be prevented by more careful supervision of children during their various activities. Intensive health education emphasising the need for early reporting to hospital after injury will greatly enhance the results of treatment. Provision of basic facilities for eye trauma management in the primary health care centres, and facilities for microsurgery and proper aphakic management in the tertiary centres, will definitely improve the outlook.

We wish to thank the ophthalmic consultants in the University of Nigeria Teaching Hospital, Enugu, for allowing us to study their patients. We are grateful to Mrs F. O. Baiyewunmi of the National Institute of Medical Research, Yaba and Ezechukwu, Federal Government College, Enugu, for secretarial assistance.

Key words: Eye injuries, Children, Visual outcome.

\section{REFERENCES}

1. National Society to Prevent Blindness: fact sheet. New York: National Society to Prevent Blindness, 1980.

2. Lindstedt E. Eye injuries in Sweden. Acta Ophthalmol (Copenh) 1966;44:590-606.

3. Olurin O. Eye injuries in Nigeria: a review of 433 cases. Am J Ophthalmol 1971;72:159-66.

4. Umeh RE. Ocular trauma: a community health approach. Orient J Med 1992;4:73-5.

5. Onwasigwe EN, Umeh RE, Onwasigwe CN. Ocular injury in children. Nig J Ophthalmol 1994;2:9-12.

6. World Health Organization. Available data on blindness (update 1987). Geneva: WHO, 1987.

7. Umeh RE. Ocular trauma in Enugu: a case study of eye injuries seen between 1980 and 1987. Fellowship Dissertation, Nigerian Postgraduate Medical College, Lagos, 1988.

8. Niiraren $\mathbf{M}$, Raivio I. Eye injuries in children. Br $\mathbf{J}$ Ophthalmol 1981;65:436-8.

9. Fong LP. Eye injuries in Victoria, Australia. Med J Aust 1995;162:64-8.

10. Abiose A. Eye injuries in Lagos: a review of 157 cases. Nig Med J 1975;5:105-7.

11. Luff AJ, Hodgkins PR, Baxter RJ, Morell AJ, Calder J. Aetiology of perforating eye injury. Arch Dis Child 1993;68:682-3.

12. Baxter RJ, Hodgkins PR, Calder I, Morrel AJ, Vardy $S$, Elkington AR. Visual outcome of childhood anterior perforating eye injuries: prognostic indicators. Eye 1994;8:349-52.

13. Rapoport I, Romem M, Kinek M, Koval R, Teller J, Belkin M, et al. Eye injuries in children in Israel. Arch Ophthalmol 1990;108:370-9 